\title{
A POLÍTICA NACIONAL DE ABRIGAMENTO DE MULHERES EM SITUAÇÃO DE RISCO E VIOLÊNCIA
}

Bruna Woinorvski de Miranda ${ }^{1}$

Resumo: Numa conjetura em que a violência contra a mulher se faz bastante presente demandando do Poder Público iniciativas que contribuam para a efetiva proteção da vítima, o presente artigo tem o intuito de promover uma análise teórica a partir do reconhecimento de legislações e recomendações que versam sobre o tema. Há enfoque na Política Nacional de Abrigamento de Mulheres em situação de risco e violência, tendo-a como principal iniciativa de proteção das vítimas em momentos urgentes - o que permite a identificação de fragilidades e possibilidades de atuação nesse contexto.

Palavras-chave: Violência contra a Mulher. Medidas de Proteção. Acolhimento Institucional.

Abstract: In front of a situation that violence against women is very actual, Government must create projects to contribute to a real protection of the victims. This article intents to promote an analysis from the bottom of legislation about this theme - violence against women. There is a focus on National Policy of sheltering women living at risk and violence, the main initiatve to protect the victims in urgent moments - it enables the identification of weaknesses and possibilities in this context.

Keywords: Violence against Women. Protective Measures. Institutional recepction.

\section{INTRODUÇÃO}

Não são recentes as situações de violência vivenciadas por mulheres em nossa sociedade. Em diferentes épocas e cenários que permeiam os espaços conjugal, social e de trabalho, a mulher figura como vítima. Resultado da cultura patriarcal que difundiu historicamente a subordinação do feminino ante ao masculino, as violações do direito da mulher perpassaram por uma longa

\footnotetext{
${ }^{1}$ Bacharel em Serviço Social (UEPG) com especializações na área da Gestão Pública (UEPG/UFPR), entre outras. Assistente Social no Tribunal de Justiça do Estado do Paraná - TJPR, com atuação no Juizado de Violência Doméstica e Familiar contra a Mulher da comarca de Ponta Grossa.
} 
trajetória até o seu reconhecimento e posterior implementação de formas de enfrentamento.

Dentro desse processo histórico, foi somente na década de 1950 que a Organização das Nações Unidas (ONU) instituiu a Comissão de Status da Mulher e criou a Declaração Universal dos Direitos Humanos, a partir de onde os direitos e liberdades começaram a ser aplicados de forma igualitária entre homens e mulheres. Em âmbito nacional, recentemente foi promulgada a Lei $\mathrm{n}^{\circ}$ 11.340/06, popularmente conhecida como "Lei Maria da Penha", que surge com o objetivo principal de erradicar toda forma de violência contra a mulher e estrutura um sistema de proteção com mecanismos de coibição e punição dos agressores.

Ainda assim, influenciadas e determinadas por diversos fatores, as agressões que violam física, psicológica e sexualmente as mulheres prosseguem permeando nossa realidade cotidianamente e causando-lhes imensuráveis danos.

Dados de um estudo preliminar realizado pelo Instituto de Pesquisa Econômica Aplicada - IPEA em 2013 apontam que entre os anos de 2009 e 2011 foram registrados no Brasil 16,9 mil casos de feminicídios - que se tratam de homicídios de mulheres causados por conflitos de gênero, especialmente oriundos de conflitos entre cônjuges. Segundo informações do Mapa de Violência (2012) o Brasil ocupa a sétima posição no ranking de países com maiores índices de violência contra a mulher.

Neste panorama, dentre as medidas e estruturas previstas, as chamadas "Casas-abrigo", destinadas ao acolhimento de mulheres que se encontram em situação de extremo risco e urgência, se mostram como importantes instrumentos de proteção a esse público.

Diante do exposto, o presente texto tem o intuito de promover, através de levantamento bibliográfico, uma análise da Política Nacional de Abrigamento de Mulheres em situação de violência e risco, apontando fragilidades e possibilidades de atuação neste contexto. Em consequência disso, torna-se possível o reconhecimento de legislações e regulamentações que versam sobre o tema, além da estrutura e funcionamento das instituições responsáveis pela execução desse serviço. 
2 RESGATE CONCEITUAL E MARCOS HISTÓRICO-

\section{LEGAIS}

A violência é algo que está presente cotidianamente em nossa sociedade. Apesar de ser expressa de diferentes modos, é empiricamente reconhecida como uma das formas de manifestação da pobreza e da exclusão social, mas sua origem e consequências nem sempre se reduzem a situações simplistas e pontuais. Nessa lógica, diferentes podem ser as definições encontradas para a violência, construídas com base em óticas distintas. De forma geral, pode-se afirmar, resumidamente, que:

A violência seria a relação social de excesso de poder que impede o reconhecimento do outro-pessoa, classe, gênero ou raça - mediante o uso da força ou da coerção, provocando algum tipo de dano, configurando o oposto das possibilidades da sociedade democrática contemporânea (TAVARES DOS SANTOS, apud PEREIRA \& PEREIRA, 2011, p. 24).

Conforme mencionado, nas relações humanas a violência pode ser manifestada de diferentes formas, através de comportamentos e ações (intencionais ou não) desenvolvidos por indivíduos nos mais variados contextos de interação (influenciados por questões culturais, econômicas, religiosas, dentre outras), trazendo consequências biopsicossociais negativas, especialmente para quem a violência foi direcionada.

\subsection{A QUESTÃO DA VIOLÊNCIA E SUAS ESPECIFICIDADES QUANTO À MULHER}

Uma breve pesquisa bibliográfica permite identificar que a mulher figura como vítima de violência (não apenas física, mas de violações em direitos básicos como à vida, a liberdade e a disposição do seu corpo) desde os tempos bíblicos. Já nessa época identifica-se que a concepção da superioridade masculina e a subordinação do feminino é presente (DIAS, 2010).

Deste modo, tem-se a reflexão de que a religião apresenta, inclusive nos dias atuais, grande influência na sociedade quanto à compreensão das funções desempenhadas pela mulher na sociedade. Assim como a religião apresenta influência histórica, identificase que outros valores pessoais e culturais perpassados ao longo do tempo também tenham repercutido na forma de educação dos filhos, contribuindo para a 
perpetuação da ideologia de superioridade masculina em nossa sociedade.

Tomando por exemplo as antigas civilizações gregas, a mulher já era compreendida como uma inferior ao homem, menosprezada moral e socialmente - motivos pelos quais não possuía direitos. Algo semelhante ocorria na Alexandria romanizada onde a mulher era tida como alma inferior e associada como símbolo de menor racionalidade; da mesma forma ao que se passou na Idade Média onde nada era permitido à mulher - a quem a única função que cabia era a de obedecer ao marido e gerar filhos. Por fim, situações semelhantes, onde se ressalta o menosprezo da figura feminina, podem ser identificadas na sociedade moderna, tal como aponta Dias (2010, p. 01):

Nas civilizações Gregas, a mulher era vista como uma criatura subumana, inferior ao homem. Era menosprezada moral e socialmente, e não tinha direito algum.

$\mathrm{Na}$ Alexandria romanizada no séc. I d.C, Filón, filósofo helenista lançou as raízes ideológicas para a subordinação das mulheres no mundo ocidental. Ele uniu a filosofia de Platão, que apontava a mulher como tendo alma inferior e menos racionalidade, ao dogma teológico hebraico, que mostra a mulher como insensata $\mathrm{e}$ causadora de todo o mal, além de ter sido criada a partir do homem.
$\mathrm{Na}$ Idade Média a mulher desempenhava o papel de mãe e esposa. Sua função precípua era de obedecer ao marido e gerar filhos. Nada lhe era permitido.

Na Idade Moderna, ao lado da queima de sutiãs em praças públicas, simbolizando a tão sonhada liberdade feminina, vimos também as esposas serem queimadas nas piras funerárias juntas aos corpos dos maridos falecidos ou incentivadas, para salvar a honra da família, a cometerem suicídio, se houvessem sido vítimas de violência sexual, mesmo se a mesma tivesse sido impetrada por um membro da família, um pai ou irmão, que nem sequer era questionado sobre o ato.

Pereira \& Pereira (2011, p. 23)

afirmam que:

As diversas formas de agressão existentes têm sua gênese no cenário cultural histórico de discriminação e subordinação das mulheres. A desigualdade criada em torno do masculino e do feminino abriu as portas para uma série de comportamentos relacionados ao domínio e ao poder de homens sobre mulheres, gerando o uso da violência. O homem historicamente recebeu da sociedade o aval para ser o chefe da casa, passando a crer que possui o direito de usar a força física sobre sua companheira ou excompanheira, como forma de impor e cobrar o comportamento que considera adequado para si e para ela.

O cenário apresentado passou a apresentar significativas mudanças a partir do capitalismo. De acordo com Pinafi (2007, p. 01), o modo de produção determinado pelo sistema capitalista: "afetou o trabalho feminino levando um 
grande contingente de mulheres às fábricas. A mulher sai do lócus que até então the era reservado e permitido - o espaço privado, e vai à esfera pública".

Nota-se que partir desse momento se iniciou um processo de contestação da compreensão disseminada acerca da inferioridade do feminino ante o masculino, resultando nos primeiros movimentos feministas que visavam à articulação de mulheres para apontar a possibilidade de ambos os sexos realizarem as mesmas tarefas. E, nesse cenário, também se passou a questionar a compreensão do direito dos homens em dominar e controlar suas mulheres, utilizando-se inclusive da violência, caso fosse necessário (PINAFI, 2007).

Contudo, o reconhecimento da questão da violência contra a mulher por organismos internacionais demorou a ocorrer. Somente em meados da década de 1950 a Organização das Nações Unidas (ONU) institui a Comissão de Status da Mulher, formulando uma série de tratados baseados em provisões da Carta das Nações Unidas (que versa sobre a igualdade dos direitos entre homens e mulheres). Em 1948 a ONU promulgou a Declaração Universal dos Direitos Humanos, que declara que todos os direitos e liberdades humanos devem ser aplicados de forma igualitária entre homens e mulheres, sem distinção de qualquer natureza.

Com a promulgação da referida declaração, diversos países passaram a reconhecer a diversidade biológica, social e cultural dos seres humanos, sendo que pactos e formas de intervenção foram sendo construídos, principalmente com o intuito de promover a igualdade entre os gêneros e lutar contra a violência contra a mulher (PEREIRA \& PEREIRA, 2011).

Já no cenário brasileiro, a década de 1970 apresenta-se como marco por se tratar do primeiro período em que foram identificados movimentos feministas organizados e politicamente engajados em defesa dos direitos da mulher contra o sistema social opressor o machismo, contribuindo para a visibilidade da questão.

O movimento "SOS Mulher" (com atividades iniciadas em São Paulo e estendidas ao Rio de Janeiro e a Porto Alegre no mesmo período), por exemplo, constituiu-se como espaço de reflexão e propositura de mudanças nas condições de vida das mulheres vítimas de violência. Trata-se de uma das primeiras iniciativas de buscar parcerias com o 
Estado que resultassem na resolução da problemática.

Acompanhando

esse

movimento e, em consonância com a dinâmica internacional, em 1979, ao ratificar a Convenção para a Eliminação de Todas as Formas de Discriminação contra a Mulher constituída a partir da Assembleia Geral das Nações Unidas, o Estado brasileiro se comprometeu perante o sistema global a coibir todas as formas de violência contra a mulher e a adotar políticas destinadas a prevenir, punir e erradicar a violência de gênero.

A Constituição da República Federativa do Brasil de 1988, visando atribuir eficácia interna à normativa internacional, de forma expressa consignou em seu texto que os direitos e garantias previstos em tratados internacionais subscritos pelo Brasil são fundamentais, assim como os elencados nos incisos de seu artigo quinto.

\subsection{LEGISLAÇÕES}

REGULAMENTAÇÕES

$\mathrm{DE}$ PROTEÇÃO À MULHER EM SITUAÇÃO DE VIOLÊNCIA

Com base em muitas discussões e num movimento que promoveu a visibilidade social e o reconhecimento da questão da violência contra a mulher, diferentes documentos foram sendo construídos no âmbito do Estado brasileiro prevendo mecanismos de prevenção da violência contra a mulher e de punição aos agressores no país, tais como a Lei 11.340/2006, o Plano Nacional de Políticas para as Mulheres, o Pacto Nacional Pelo Enfrentamento à Violência contra a Mulher, dentre outras regulamentações.

A Lei $n^{\circ}$ 11.340/06 representa um marco na luta contra a violência contra a mulher. Tendo como objetivo principal a erradicação de toda forma de violência contra a mulher, tal legislação recebeu esse nome em homenagem à Maria da Penha Maia Fernandes mulher brasileira vítima de violência que buscou até os últimos recursos $^{2}$ para
2 Após sofrer duas tentativas de homicídio num período de dois anos, Maria da Penha denunciou o seu marido que, tendo ido a júri, ficou preso por apenas dois anos após recorrer da sentença. Uma vez que não logrou êxito junto à justiça brasileira, Maria buscou auxílio em uma Organização Não-Govenamental (o CEJIL - Centro pela Justiça e o Direito Internacional) que visa alcançar a plena implementação das normas internacionais de direitos humanos e, com o apoio do CLADEM (Comitê Latino-Americano e do Caribe para a 
evidenciar socialmente a importância de proteger as mulheres da violência sofrida no ambiente doméstico e/ou familiar.

A Lei trouxe alterações significativas no âmbito da justiça criminal, enrijecendo o sistema punitivo para o agressor e adotando mecanismos de proteção mais efetivos. Segundo levantamento feito pela Defensoria Pública do Estado de São Paulo, a lei afastou a incidência dos institutos despenalizadores da Lei 9.095/95; passou a impedir a composição de danos e a suspensão condicional do processo nos casos de violência doméstica; determinou que deixasse de ser lavrado o termo circunstanciado, e passasse a ser permitido o auto de prisão em flagrante do autor de violência; além de versar que a denúncia da violência doméstica deve ser feita por escrito, e não de forma oral (SÃO PAULO, 2009).

Ademais, tem-se ainda que a Lei Maria da Penha tornou a lesão leve decorrente de violência doméstica objeto de ação pública incondicionada; deixou de permitir a aplicação de penas alternativas nos mesmos casos; possibilitou a decretação de prisão preventiva nos casos de violência doméstica; bem como passou a prever que, nos crimes em que é permitida a retratação, esta seja realizada em audiência específica para este fim (SÃO PAULO, 2009).

A norma prevê ainda medidas protetivas de urgência que vão desde a saída compulsória do agressor do domicílio, a proibição de sua aproximação da mulher agredida e a suspensão ou restrição de posse de arma pelo autor da violência, tudo para que lhe seja assegurada a sua proteção.

Interessante destacar que, muito embora o senso comum associe a "violência" apenas às violações de integridade física, ela pode se manifestar das mais diversas formas, de modo que qualquer ato que cerceie os seus direitos: “à vida, à segurança, à saúde, à alimentação, à educação, à cultura, à moradia, ao acesso à justiça, ao esporte, ao lazer, ao trabalho, à cidadania, à liberdade, à dignidade, ao respeito e à convivência familiar e comunitária" (Art. $3^{\circ}$ da Lei 11. 340/2006), pode ser configurado como violência.
Defesa dos Direitos da Mulher), denunciou o Brasil na Comissão Interamericana de Direitos Humanos da OEA (Organização dos Estados
Americanos) pela negligência do país em tratar os casos de violência doméstica. 
A Lei Maria da Penha intitula “doméstica" a violência perpetrada no espaço de convívio permanente das pessoas, com ou sem vínculo de parentesco, e "familiar" a violência ocorrida no espaço da família, ou seja, dentro do grupo de pessoas que são ou se consideram aparentados (unidos por laços naturais, por afinidade ou por vontade expressa). O referido diploma legal nos diz ainda que se considera:

a) violência física: qualquer ação que atinja a saúde corporal da mulher;

b) violência psicológica: caracterizada pelo controle das ações, comportamento ou decisões da mulher. Geralmente se manifesta na forma de ameaças, intimidações, manipulação, humilhações ou qualquer outra forma que traga prejuízos à saúde mental e emocional da mulher;

c) violência moral: voltada às práticas de caluniar, injuriar ou difamar a mulher,

d) violência patrimonial: se refere a ações que atentem contra o patrimônio da mulher, ou seja, quando o agressor toma posse ou destrói objetos pessoais da vítima (como documentos, roupas, instrumentos de trabalho ou bens); e,
50

e) violência sexual: entendida como ações que obrigam a mulher a participar, presenciar ou manter relações sexuais sob o uso de força física, chantagem, ameaças ou intimidações. Relaciona-se também com a ação de forçar a mulher a prática do aborto, prostituição, ou ainda, que a impeça de utilizar mecanismos contraceptivos.

Em suma, a Lei Maria da Penha é o principal instrumento de proteção à mulher em situação de violência no Brasil, resultante de movimentos que contribuíram para a maior visibilidade da problemática. Contudo, de modo paralelo já ocorria a ampliação do debate acerca do tema que levou à sistematização da intervenção estatal no que concerne às mulheres, tal como ocorre com o Plano Nacional de Políticas para Mulheres.

O Plano Nacional de Políticas para as Mulheres, datado de 2005, é resultado das discussões realizadas na I Conferência Nacional de Políticas para as Mulheres, que contou com mais de 120 mil participantes em 2004 na capital do país, Brasília. Trata-se de uma iniciativa da Secretaria Especial de Políticas para as Mulheres que expõe os objetivos e metas do governo federal, 
além das linhas de ações para a promoção dos direitos das mulheres.

Pautando-se na Política Nacional para as Mulheres (que se orienta pela igualdade e respeito à diversidade, além da equidade aos indivíduos, autonomia das mulheres, laicidade do Estado, universalidade das políticas, justiça social, transparência dos atos públicos e participação e controle social), o Plano Nacional de Políticas para as Mulheres considera que: "o maior acesso e participação das mulheres nos espaços de poder são instrumentos essenciais para democratizar o Estado e a sociedade" (BRASIL, 2005, p. 09).

Ademais, as ações do Plano foram traçadas com base em quatro eixos de atuação considerados mais urgentes para garantir o direito a uma vida melhor para todas as mulheres, a saber: a) a autonomia, igualdade no mundo do trabalho e cidadania; b) educação inclusiva e não sexista; c) saúde, direitos sexuais e direitos reprodutivos; e d) enfrentamento à violência contra as mulheres.

No que se refere ao enfrentamento à violência contra as mulheres, tratam-se de objetivos a implantação de uma política coesa e integrada; a redução dos índices de violência e a garantia do atendimento integral, humanizado e de qualidade às vítimas, além do cumprimento dos instrumentos e acordos internacionais e da revisão da lesgislação brasileira quanto o tema.

O diagnóstico situacional da violência contra a mulher no país é apontado como primeiro passo para o desenvolvimento das ações previstas para o enfrentamento à violência contra as mulheres. Ademais, a integração das políticas e dos serviços especializados, especialmente na forma de rede, bem como a estruturação do trabalho são mencionados como importantes estratégias de atuação neste eixo.

Outro grande marco no Brasil, o Pacto Nacional Pelo Enfrentamento à Violência contra a Mulher firmado no ano de 2007 reconhece a necessidade da adoção de Políticas Públicas, de caráter universal, acessíveis a todas as mulheres que englobem as diferentes modalidades nas quais a violência se expressa, considerando que são muito frequentes situações de violação de direito e de violência contra mulheres.

Dessa forma, o referido documento trata de diversas ações a serem adotadas com o intuito de 
responsabilizar agressores, mas, sobretudo, evitar que a violência aconteça, estabelecendo metas a serem alcanças em determinados prazos.

Para tanto, também considera como importante instrumento a articulação do Poder Público (nas diferentes Políticas e âmbitos de atuação) e da sociedade civil para a construção de uma cultura da paz e de respeito aos direitos humanos de todas as pessoas, inclusive mulheres, conforme regem as legislações, além de almejar a estruturação e ampliação de serviços especializados, tais como delegacias da mulher, casas-abrigo, centros de referência, dentre outros.

São objetivos do Pacto Nacional Pelo Enfrentamento à Violência contra a Mulher a redução dos índices de violência contra a mulher; a promoção da mudança cultural partindo da disseminação de ações igualitárias e valores éticos que respeitem às diversidades de gênero e valorização da paz; e a garantia e proteção dos direitos das mulheres em situação de violência, considerando as influências e diversidades raciais, étnicas, geracionais, de orientação sexual, de deficiência e de inserção social, econômica e regional (BRASIL, 2007a).

Considerando a amplitude das discussões e a influência de diferentes elementos na questão da violência contra a mulher, diferentes Políticas Públicas trataram de organizar e regulamentar sua atuação quanto à problemática emergida.

Ademais, reconhece-se, no âmbito do Poder Judiciário, significativas contribuições no cenário da luta contra a violência contra a mulher, tal como quando o Conselho Nacional da Justiça (CNJ) publicou a Recomendação $n^{\circ} 9$ de 2007, que orienta aos Tribunais de Justiça criar Juizados Especializados em Violência Doméstica e Familiar contra a Mulher - o que passou a ser implantado gradativamente em âmbito nacional ${ }^{3}$.

Há também a Resolução $\mathrm{n}^{\circ}$ 128/11 do CNJ que determinou, em todos os Tribunais de Justiça do país e nas suas respectivas estruturas administrativas, a criação de Coordenadorias Estaduais da Mulher em Situação de Violência para funcionarem como órgãos permanentes de assessoria

3 Segundo informações do Conselho Nacional da Justiça, desde o advento da Lei Maria da Penha em 2006 até 2012 foram implantadas 66 varas ou juizados com competência exclusiva para o processamento e julgamento de crimes contra a mulher (BRASIL, 2013). 
da presidência. Num mesmo viés, o Conselho publicou o Manual de Rotinas e Estruturação dos Juizados de Violência Doméstica e Familiar contra a Mulher padronizando os procedimentos e prevendo estruturação física e humana para o seu adequado funcionamento.

Neste cenário, há destaque ainda, para a Campanha "Compromisso e Atitude", de iniciativa da Secretaria Nacional de Políticas para as Mulheres, que tem como principal objetivo promover o diálogo entre os três Poderes visando reduzir as desigualdades de gênero por meio das mais diversas Políticas Públicas. Para tanto, há grande importância na cooperação estabelecida entre o Poder Judiciário, Ministério Público, Defensoria Pública e Governo Federal na construção desse trabalho.

De forma geral, nota-se que ao longo dos anos a questão da violência contra a mulher tornou-se foco para o Estado, demandando deste a promulgação de legislações e criação de mecanismos de coibição da violência, de responsabilização dos agressores, mas, principalmente, de proteção da mulher.

\subsection{A MEDIDA PROTETIVA DE} ACOLHIMENTO INSTITUCIONAL
Medidas Protetivas ou de Proteção são iniciativas concedidas através de processo judicial e adotadas pelos órgãos competentes, especialmente vinculados ao Poder Judiciário ou instituições do Poder Executivo que abordam casos de ameça ou violação de direitos, com o intento de fazer cessar ou minimizar situações de violência e/ou risco a que se encontram submetidas pessoas em condições de vulnerabilidade.

Conforme o Programa Federal de Assistência a Vítimas e a Testemunhas Ameaçadas, instituído pela Lei $n^{\circ}$ 9.807/99,

Art. $1^{\circ}$ As medidas de proteção
requeridas por vítimas ou por
testemunhas de crimes que estejam
coagidas ou expostas a grave
ameaça em razão de colaborarem
com a investigação ou processo
criminal serão prestadas pela
União, pelos Estados e pelo
Distrito Federal, no âmbito das
respectivas competências, na
forma de programas especiais
organizados com base nas
disposições desta Lei.

Assim, cabe ao Poder Público a organização e manutenção de programas e iniciativas que contribuam para a sua efetivação. E, em se tratando de mulheres em situação de violência que se encontram em extremo risco, a medida protetiva do acolhimento institucional é 
tida como a principal forma de intervenção estatal.

Conforme informações da Secretaria Nacional de Políticas para as Mulheres:

No Brasil, a primeira Casa-Abrigo é implantada em São Paulo, em 1986 - Centro de Convivência para Mulheres Vítimas de Violência Doméstica (Convida). Em 1990, é criada a Casa-Abrigo de Santo André/SP; em 1991, a Casa Helenira Rezende de Souza Nazareth /SP; em 1992, a Casa Abrigo Viva Maria/RS e a Casa do Caminho/CE; e em 1996, a CasaAbrigo do Distrito Federal e a Casa-Abrigo Sempre-Viva/MG (BRASIL, 2011, p. 31).

Logo, vê-se o quão recente é tal modalidade de atendimento na realidade brasileira, que passou a ser regulamentada apenas no final dos anos 2000, especialmente quando o Conselho Nacional de Assistência Social - CNAS aprovou, através da Resolução $\mathrm{n}^{\circ}$ 109/2009, a tipificação dos serviços socioassistenciais dentre os quais, elencado como Serviço de Proteção Social Especial de Alta Complexidade. Neles, há a modalidade de acolhimento institucional voltado a populações expostas a vulnerabilidades ou risco, estando as mulheres em situação de violência incluídas nesse público.

A referida resolução define a modalidade de acolhimento institucional de mulheres em situação de violência como:

\begin{abstract}
Acolhimento provisório para mulheres, acompanhadas ou não de seus filhos, em situação de risco de morte ou ameaças em razão da violência doméstica e familiar, causadora de lesão, sofrimento físico, sexual, psicológico ou dano moral. Deve ser desenvolvido em local sigiloso, com funcionamento em regime de co-gestão, que assegure a obrigatoriedade de manter o sigilo quanto à identidade das usuárias. Em articulação com rede de serviços socioassistenciais, das demais políticas públicas e do Sistema de Justiça, deve ser ofertado atendimento jurídico e psicológico para as usuárias e seus filhos e/ou dependente quando estiver sob sua responsabilidade (BRASIL, 2013, p. 41).
\end{abstract}

Todavia, apesar de ser elencado como serviço socioassistencial, o abrigamento de mulheres em situação de violência e risco tem seu funcionamento e estrutura regulamentados pelas Diretrizes Nacionais para o Abrigamento de Mulheres em Situação de Violência e Risco - documento da Secretaria Nacional de Políticas para as Mulheres que redefine as possibilidades de acolhimento provisório desse público com o intuito de promover-lhes segurança e proteção.

Vale ressaltar a distinção entre Casas-Abrigo de Casas de Acolhimento trazidas pelas Diretrizes Nacionais para o Abrigamento de Mulheres em Situação 
de Violência ou Risco, uma vez que as primeiras são aquelas constituídas com base nos serviços socioassistenciais e objetivam o atendimento de mulheres em situação de grave ameaça ou sob risco de morte por meio de acolhimento de longa duração, enquanto que as últimas não são vinculadas aos serviços socioassistenciais, possuem caráter sigiloso e podem acolher, por curtos períodos, mulheres que estão em situação de violência independente da existência do risco de morte. Contudo, a situação de violência exige cautela e atendimento especializado das vítimas, o que evidencia a complexidade dos serviços de institucionalização, uma vez que:

O abrigamento [...] não se refere somente aos serviços propriamente ditos (albergues, casas-abrigo, casas-de-passagem, casas de acolhimento provisório de curta duração, etc), mas também inclui outras medidas de acolhimento que podem constituirse em programas e benefícios ${ }^{4}$ (benefício eventual para os casos de vulnerabilidade temporária) que assegurem o bem-estar físico, psicológico e social das mulheres em situação de violência, assim como sua segurança pessoal e familiar (BRASIL, 2011, p. 15).
Assim, o atendimento às vítimas institucionalizadas deve ser acompanhado pelos serviços da rede de enfrentamento local, bem como da articulação com a segurança pública para a sua efetiva proteção.

O Termo de Referência para a Implementação de Casas-Abrigo para mulheres em situação de violência, também redigido pela Secretaria Nacional de Políticas para as Mulheres, versa que o principal objetivo institucional deve primar pela garantia da integridade: "física e psicológica de mulheres em risco de morte e de seus filhos de menor idade, favorecendo o exercício de sua condição cidadã; resgatando e fortalecendo sua autoestima; e possibilitando que se tornem protagonistas de seus próprios direitos" (BRASIL, 2008, p. 12).

Para tanto, cabe a tais instituições propiciar o atendimento de forma integral e interdisciplinar às mulheres e respectivos dependentes, especialmente nas áreas psicológica, social e jurídica, bem como articular suas ações com programas de saúde, emprego

do Sistema Único de Assistência Social - SUAS. Assim, os benefícios eventuais incluem: o auxílio por natalidade, o auxílio por morte, o benefício nos casos de calamidade pública e de vulnerabilidade temporária (BRASIL, 2011, p. 22).

\footnotetext{
${ }^{4}$ Segundo o decreto $\mathrm{n}^{\circ}$. 6.307/2007, os benefícios eventuais são provisões suplementares e provisórias, prestadas aos cidadãos e às famílias em virtude de nascimento, morte, situações de vulnerabilidade temporária e de calamidade pública, que integram organicamente as garantias
}

5


e renda, moradia, creches, profissionalização, entre outros. A promoção de suporte informativo e do acesso a serviços a partir da instrução das mulheres para que reconheçam os seus direitos como cidadãs e os meios para efetivá-los também deve ser instigado enquanto perdurar a institucionalização, da mesma forma que contribuir para a construção de um ambiente onde as mulheres exercitem a sua autonomia e tenham a possibilidade de recuperar a sua auto-estima deve ser almejado.

Para que supram as necessidades das mulheres e dependentes em situação de violência ou risco no período em que perdurar a institucionalização, o Termo de Referência indica, ainda, uma estrutura física mínima necessária, que deve contemplar:

1. Imóvel de dimensões adequadas com $10 \mathrm{~m} 2$ por pessoa, conforme normas da ABNT - Associação Brasileira de Normas Técnicas, para abrigar o número estabelecido de mulheres e seus filhos de menor idade, em local que favoreça a segurança e o sigilo. 2. Localização do abrigo, de preferência em área residencial, não contando com presença aparente de guaritas, placas de identificação, oferecendo um ambiente discreto e propício (BRASIL, 2008, p. 16-17).

O sigilo aparece como uma condição necessária para a proteção das vítimas e familiares, e espaço estimado visa o acolhimento com conforto e privacidade adequados às acolhidas.

De forma complementar, também há maior especificação inerente ao espaço institucional, bem como a regulamentação quanto aos recursos materiais que devem ser disponibilzados nos referidos abrigos, a saber:

- Espaço para dormitórios, onde a mulher possa acomodar seus pertences pessoais, mantendo o vínculo familiar e garantindo sua privacidade;

- Espaços de convivência coletiva (salas de reuniões, grupos e oficinas);

- Espaços para o refeitório e cozinha coletiva;

- Espaço para recreação das crianças, preferencialmente contando com áreas externas;

- Local adequado ao atendimento de primeiros socorros, guarda de medicamentos e outras ações de profilaxia em saúde;

- Espaço para lavanderia coletiva;

- Dependências sanitárias compatíveis com o número de pessoas abrigadas;

- Adequação da estrutura do imóvel aos portadores de necessidades especiais, garantindo a acessibilidade;

- Espaço adequado para a equipe técnica e administrativa, resguardando o sigilo relativo às usuárias do serviço;

- Infra-estrutura administrativa de comunicação e de transporte (BRASIL, 2008, p. 16).

Nota-se que a previsão dos recursos físicos e materiais são consonantes aos objetivos do acolhimento de mulheres em situação de 
violência ou risco e seus respectivos familiares no que tange não apenas à segurança, discrição e sigilo, mas também ao propiciar local acolhedor, acessível e que se aproxime e retome muito do seu espaço cotidiano para que ocorra, por parte das vítimas, a superação da problemática num processo de empoderamento e resiliência.

Por fim, para os abrigos também há uma previsão de recursos humanos necessários para o suporte das vítimas institucionalizadas, classificadas, pelo Termo de Referência, em três equipes principais:

I) equipe interdisciplinar permanente, composta por profissionais de nível superior que atendam as áreas de saúde física, mental e promoção de cidadania (envolvendo a coordenação do serviço e demais profissionais especializados, como psicólogo, assistente social, pedagogo ou profissional da área de educação infantil);

II) equipe de apoio técnico, que não precisa ser exclusiva da instituição e conta com profissionais de nível superior de suporte à saúde, nutrição, orientação e assistência jurídica às moradoras (tais como nutricionista, enfermeiro e advogado); e
III) equipe operacional, que envolve profissionais de nível médio e/ou básico que atuem no provimento da infraestrutura (incluindo agente administrativo, cozinheira, auxiliar de conservação e limpeza, segurança e motorista).

Em suma, atentas às demandas provenientes da questão da violência contra a mulher, legislação e demais normativas representam um grande avanço para a proteção das vítimas de agressões, prevendo importantes iniciativas para a superação da problemática e empoderamento da mulher. Porém, a estruturação e o alinhamento desses serviços dentro da Política Nacional de Abrigamento de Mulheres em Situação de Risco e Violência no país ainda é algo que parece em construção.

\section{A IMPLEMENTAÇÃO DA POLÍTICA NACIONAL DE ABRIGAMENTO DE MULHERES EM SITUAÇÃO DE RISCO E VIOLÊNCIA}

As multifacetas e a complexidade que o fenômeno da violência contra a mulher apresenta nos seus diversos modos de expressão, 
demandaram do Estado iniciativas de prevenção e combate a tal forma de violação de direito do público feminino, especialmente através de políticas de caráter universal acessíveis a todas as mulheres.

Nessa lógica,

A Política Nacional amplia o conceito de violência contra as mulheres (fazendo referência a diversos tipos de violência, tais como a violência doméstica e familiar contra a mulher, o assédio sexual, a violência institucional, o tráfico de mulheres, etc) e passa a incluir quatro dimensões/eixos para o enfrentamento à violência contra as mulheres: a prevenção, o combate, a assistência e a garantia de direitos (BRASIL, 2011, p. 10).

Ademais, fica clara a importância da atuação de redes interinstitucionais e intersetoriais no processo de enfrentamento à violência contra a mulher, especialmente no que tange às situações em que há acolhimento institucional das vítimas que, via de regra, se encontram em maior situação de vulnerabilidade e risco. No sentido de implementar as ações de enfrentamento, "a Política Nacional se articula com diversas outras políticas, a saber: a Política Nacional de Enfrentamento ao Tráfico de Pessoas, a Política Nacional de Assistência Social, a Política Nacional de Saúde das
Mulheres, entre outras" (BRASIL, 2011, p. 10).

Contudo, apesar de toda a trajetória percorrida e do empenho do Estado na implantação de ações de proteção da mulher em situação de violência ou risco, ainda se mostram muito incipientes tais iniciativas. Isso porque, quanto à existência de serviços especializados de gestão Municipal para atendimento de mulheres em situação de violência, segundo a Pesquisa de Informações Básicas Municipais MUNIC de 2013, apenas:

[...] 21,7\% das cidades ofertavam algum desses tipos de programas, como delegacias e juizados especializados. A oferta deles era maior em cidades com mais de 500 mil habitantes $(85 \%)$ e muito baixa nas com até 10 mil habitantes (menos que 10\%). Segundo o IBGE, há cidades em que não havia sequer uma creche, estrutura apontada como aspecto importante para a política de empoderamento das mulheres. Nos Municípios com até 5 mil habitantes, $42,3 \%$ não tinham uma estrutura como essa (RIBEIRO, 2016, p. 01).

Tal informação vai de encontro com as informações divulgadas em 2013 pelo Instituto Brasileiro de Geografia e Estatística - IBGE no que tange aos municípios brasileiros que contam com planos e políticas específicas para as mulheres (tabela 1). Conforme os dados divulgados, dos 5570 municípios do 
país, apenas 250 contavam com Plano Municipal para as Mulheres, sendo que somente 86 destes possuíam previsão legal do trabalho.

No Estado do Paraná a realidade não é muito distinta: dos 399

TABELA 1 - MUNICÍPIOS, TOTAL E COM PLANO MUNICIPAL DE POLÍTICAS PARA AS MULHERES, SEGUNDO AS GRANDES REGIÕES E AS UNIDADES DA FEDERAÇÃO - 2013.

\begin{tabular}{c|c|c|c|c}
\hline \multirow{2}{*}{$\begin{array}{c}\text { Grandes Regiões } \\
\text { e }\end{array}$} & & \multicolumn{4}{|c}{ Municípios } \\
\cline { 4 - 5 } Unidades da Federação & Total & Total & Com ou sem previsão legal \\
\cline { 4 - 5 } & & & $\begin{array}{c}\text { Com previsão } \\
\text { legal }\end{array}$ & $\begin{array}{c}\text { Sem previsão } \\
\text { legal }\end{array}$ \\
\hline Brasil & $\mathbf{5 5 7 0}$ & $\mathbf{2 5 0}$ & $\mathbf{8 6}$ & $\mathbf{1 6 4}$ \\
Sul & $\mathbf{1 1 9 1}$ & $\mathbf{3 4}$ & $\mathbf{1 5}$ & $\mathbf{1 9}$ \\
Paraná & 399 & 8 & 3 & 5 \\
Santa Catarina & 295 & 5 & 2 & 3 \\
Rio Grande do Sul & 497 & 21 & 10 & 11 \\
\hline
\end{tabular}

Fonte: IBGE, Diretoria de Pesquisas, Coordenação de População e Indicadores Sociais, Pesquisa de Informações Básicas Municipais 2013 (compilado).

Não havendo Plano Municipal de Políticas para as Mulheres, infere-se que, especialmente aquelas que se encontram em situação de violência, municípios do estado, somente 8 possuíam Plano Municipal de Políticas para as Mulheres, dos quais apenas 3 com previsão legal.

TABELA 2 - MUNICÍPIOS, TOTAL E COM SERVIÇOS ESPECIALIZADOS DE GESTÃO MUNICIPAL PARA MULHERES EM SITUAÇÃO DE VIOLÊNCIA DE ACORDO COM A LEI MARIA DA PENHA, SEGUNDO AS GRANDES REGIÕES E AS UNIDADES DA FEDERAÇÃO - 2013.

\begin{tabular}{l|c|c|c}
\hline \multirow{2}{*}{$\begin{array}{l}\text { Grandes } \\
\text { Regiões } \\
\text { e } \\
\text { classes de }\end{array}$} & \multirow{2}{*}{ Total } & \multicolumn{2}{c}{ Municípios } \\
\cline { 2 - 4 } & & Total & $\begin{array}{c}\text { Com Serviços Especializados de gestão municipal para mulheres em situação de } \\
\text { violência de acordo com a Lei Maria da Penha }\end{array}$ \\
\cline { 2 - 3 } & & \multicolumn{2}{c}{ Tipo de atividade realizada } \\
\hline
\end{tabular}




\begin{tabular}{|c|c|c|c|c|c|c|c|c|c|c|c|}
\hline \multirow[b]{2}{*}{$\begin{array}{c}\text { tamanho da } \\
\text { população dos } \\
\text { municípios }\end{array}$} & & & & & & & & & \multicolumn{3}{|c|}{60} \\
\hline & & & $\begin{array}{c}\text { Atendi- } \\
\text { mento } \\
\text { psicoló- } \\
\text { gico } \\
\text { indi- } \\
\text { vidual }\end{array}$ & $\begin{array}{l}\text { Atendi- } \\
\text { mento } \\
\text { psicoló- } \\
\text { gico em } \\
\text { grupo }\end{array}$ & $\begin{array}{l}\text { Ativida- } \\
\text { des } \\
\text { culturais } \\
\text { e edu- } \\
\text { cativas } \\
\text { profis- } \\
\text { sionali- } \\
\text { zantes }\end{array}$ & $\begin{array}{l}\text { Atendi- } \\
\text { mento } \\
\text { jurídico }\end{array}$ & $\begin{array}{l}\text { Atendimento } \\
\text { social } \\
\text { acompa- } \\
\text { nhado por as- } \\
\text { sistente } \\
\text { social } \\
\text { que insira a } \\
\text { mulher em } \\
\text { programas } \\
\text { sociais do } \\
\text { governo, } \\
\text { como Bolsa- } \\
\text { Família e/ou } \\
\text { Benefícios de } \\
\text { Prestação } \\
\text { Continuada }\end{array}$ & $\begin{array}{c}\text { Enca- } \\
\text { minha- } \\
\text { mento } \\
\text { para } \\
\text { pro- } \\
\text { gramas } \\
\text { de em- } \\
\text { prego e } \\
\text { geração } \\
\text { de } \\
\text { renda }\end{array}$ & $\begin{array}{c}\text { Ativida- } \\
\text { des de } \\
\text { cons- } \\
\text { cientiza- } \\
\text { ção so- } \\
\text { bre os } \\
\text { direitos } \\
\text { da } \\
\text { mulher } \\
\text { junto à } \\
\text { comu- } \\
\text { nidade }\end{array}$ & $\begin{array}{c}\text { Acom- } \\
\text { panha- } \\
\text { mento } \\
\text { nos } \\
\text { casos } \\
\text { da Lei } \\
\text { Maria } \\
\text { da } \\
\text { Penha }\end{array}$ & $\begin{array}{l}\text { Outr } \\
\text { as } \\
\text { ativi } \\
\text { da- } \\
\text { des }\end{array}$ \\
\hline Brasil & 5570 & 1210 & 1075 & 649 & 522 & 871 & 1040 & 704 & 850 & 860 & 266 \\
\hline Sul & 1191 & 271 & 233 & 127 & 99 & 135 & 227 & 159 & 160 & 173 & 42 \\
\hline Paraná & 399 & 90 & 79 & 38 & 26 & 57 & 79 & 59 & 56 & 65 & 15 \\
\hline $\begin{array}{l}\text { Santa Catarina } \\
\text { Rio Grande do }\end{array}$ & 295 & 81 & 67 & 40 & 28 & 34 & 64 & 49 & 46 & 48 & 11 \\
\hline & 497 & 100 & 87 & 49 & 45 & 44 & 84 & 51 & 58 & 60 & 16 \\
\hline
\end{tabular}

Fonte: IBGE, Diretoria de Pesquisas, Coordenação de População e Indicadores Sociais, Pesquisa de Informações Básicas Municipais 2013 (compilado).

A tabela acima demonstra que $11 \%$ dos municípios do país e $9 \%$ dos municípios do estado do Paraná dispõem de atendimento psicológico individual à mulher em situação de violência, sendo esse número menor para os atendimentos psicológicos individuais, aonde se constata disponibilidade em apenas 19\% das cidades em âmbito nacional e estadual.

Quanto a atividades culturais, educativas e profissionalizantes, identifica-se que elas são desenvolvidas em apenas 9\% dos municípios brasileiros e em 6\% das cidades do Paraná. Já o atendimento jurídico à mulher vítima de violência é disponibilizado em cerca de
$15 \%$ das cidades no país e Estado do Paraná.

O atendimento social acompanhado por assistente social que insira a mulher em programas sociais do governo, como Bolsa-Família e/ou Benefícios de Prestação Continuada é realizado em 19\% dos municípios em âmbito federal e no Estado do Paraná, enquanto que o encaminhamento de mulheres em situação de violência para programas de emprego e geração de renda ocorre em $12 \%$ dos municípios brasileiros e 14\% das cidades do Paraná.

Atividades de conscientização sobre os direitos da mulher junto à comunidade, por sua vez, são desenvolvidas em $15 \%$ e $14 \%$ dos 
municípios do Brasil e do Paraná, respectivamente. Também gira em torno de $15 \%$ os municípios do país e do Estado em que são realizados acompanhamentos nos casos provenientes da Lei Maria da Penha. E, por fim, aproximadamente $4 \%$ destas cidades dispõem de outros serviços de atendimento à mulher em situação de violência.

Em análise aos dados apresentados que, de forma geral, revelam baixos índices de serviços disponibilizados à mulher em situação de violência, pondera-se que a problemática advém do fato de que as Políticas Públicas dispõem de serviços especializados apenas em municípios de maior porte, limitando assim, o atendimento da população que depende dos seus serviços - o que deve demandar atenção do Poder Público para que ninguém fique à margem do atendimento que necessita.

Quando se fala do acesso aos serviços de proteção por mulheres em situação de violência, especialmente quanto ao acolhimento institucional, também se constata realidade aquém do esperado, haja vista que:

Segundo os dados do sistema da rede de atendimento à mulher da
Secretaria de Políticas para as Mulheres, as mulheres em situação de violência têm acesso a um número reduzido de serviços de abrigamento no país, que, em geral, referem-se somente aos casos de violência doméstica e familiar (casas-abrigo) e alguns serviços de acolhimento provisório de curta duração (BRASIL, 2011, p. 25).

Nesse caso é bastante comum, país afora, existirem outros serviços de abrigamento que acabam por acolher as demandas de mulheres em situação de violência, tais como albergues, pastorais da mulher, repúblicas, dentre outros - o que está longe do ideal, pois, como já enfatizado, a abordagem da violência de mulheres e seus dependentes é complexa e deveria preconizar a prestação de atendimento especializado em articulação com outros setores e políticas públicas.

Tem-se, ainda, que:

Segundo dados da Secretaria de Políticas para as Mulheres (SPM, 2009), havia um total de 42 casasabrigo no país. Atualmente, existem 72 casas-abrigo no território brasileiro. A maior concentração de Casas-Abrigo encontra-se no Sudeste do país (25 equipamentos) e no Sul (13 equipamentos). Trinta e sete por cento das unidades da federação (10 UFs) possuem apenas 1 CasaAbrigo. A maioria dos equipamentos encontra-se vinculada à gestão da Assistência Social, com algumas exceções em que as Casas-Abrigo estão ligadas à Segurança Pública, à Justiça ou a Saúde. Em sua maioria, os 
serviços são governamentais (constituem serviços municipais e/ou estaduais) e sigilosos (BRASIL, 2011, p. 31).

Nota-se, com base nesses dados que houve um aumento no número de instituições aptas para o abrigamento de mulheres em situação de violência no país de 2009 para 2011. Porém, ainda se considera o número pouco expressivo para a realidade nacional de mais de cinco mil municípios. As informações dão conta ainda de que mais da metade dos serviços está localizada nas regiões sul e sudeste do país, podendo significar que as mulheres das outras regiões se encontram à margem do atendimento.

Como aspecto positivo, verifica-se que a maior parte dos serviços está regulamentado e submetido à gestão governamental - o que pode significar maior destinação de recursos e continuidade nos serviços.

Pautando-se nas informações divulgadas pelo IBGE através do MUNIC de 2013, Ribeiro (2016, p. 01) aponta que:
Apenas 2,5\% das cidades brasileiras têm casas-abrigo para mulheres em situações de violência, [...] Segundo o IBGE, o problema é especialmente preocupante nos municípios menos populosos, com até $20 \mathrm{mil}$ habitantes (que correspondem a $70 \%$ do total de cidades do País), pois havia apenas 16 delas em 3.852 cidades. Em $61,5 \%$ das localidades com mais de 500 mil habitantes havia esse tipo de estrutura.

Dados fornecidos pelo IBGE quanto ao total de Casas-abrigo existentes no país com ênfase na região sul, além de corroborar a informação de que menos de $3 \%$ dos municípios brasileiros dispõem de Casas-Abrigo, também evidenciam uma realidade que demanda atenção do Poder Público: os critérios de atuação e os atendimentos que deveriam ser disponibilizados nas referidas instituições, conforme regulamentam as Diretrizes Diretrizes Nacionais para o Abrigamento de Mulheres em Situação de Violência e Risco, não estão presentes na totalidade das Casas-abrigo (tabela 3).

TABELA 3 - MUNICÍPIOS, TOTAL E COM CASA-ABRIGO PARA ATENDIMENTO A MULHERES VÍTIMAS DE VIOLÊNCIA, SEGUNDO AS GRANDES REGIÕES E AS UNIDADES DA FEDERAÇÃO - 2013 


\begin{tabular}{|c|c|c|c|c|c|c|c|c|c|}
\hline \multirow[b]{3}{*}{$\begin{array}{c}\text { Grandes } \\
\text { Regiões } \\
\text { e } \\
\text { Unidades } \\
\text { da } \\
\text { Federação }\end{array}$} & \multirow[b]{3}{*}{ Total } & \multicolumn{8}{|c|}{$\begin{array}{l}\text { Com Casa-Abrigo para atendimento a mulheres vítimas de } \\
\text { violência de acordo com a Lei Maria da Penha }\end{array}$} \\
\hline & & \multirow[b]{2}{*}{$\begin{array}{c}\text { Total } \\
(1)\end{array}$} & \multirow[b]{2}{*}{$\begin{array}{l}\text { Quanti- } \\
\text { dade }\end{array}$} & \multirow[b]{2}{*}{$\begin{array}{l}\text { Com } \\
\text { todas } \\
\text { as } \\
\text { casas } \\
\text { com } \\
\text { ende- } \\
\text { reço } \\
\text { sigiloso }\end{array}$} & \multicolumn{5}{|c|}{ Tipo de atividade realizada } \\
\hline & & & & & $\begin{array}{c}\text { Aten- } \\
\text { dimento } \\
\text { psico- } \\
\text { lógico } \\
\text { indi- } \\
\text { vidual }\end{array}$ & $\begin{array}{l}\text { Aten- } \\
\text { dimento } \\
\text { psico- } \\
\text { lógico } \\
\text { em } \\
\text { grupo }\end{array}$ & $\begin{array}{l}\text { Ativi- } \\
\text { dades } \\
\text { culturais } \\
\text { e edu- } \\
\text { cativas }\end{array}$ & $\begin{array}{l}\text { Ativi- } \\
\text { dades } \\
\text { profis- } \\
\text { sionali- } \\
\text { zantes }\end{array}$ & $\begin{array}{c}\text { Atendimento } \\
\text { social acom- } \\
\text { panhado por } \\
\text { assistente so- } \\
\text { cial que insira } \\
\text { a mulher em } \\
\text { programas } \\
\text { sociais do } \\
\text { governo, } \\
\text { como Bolsa- } \\
\text { Família e/ou } \\
\text { Benefícios de } \\
\text { Prestação } \\
\text { Continuada }\end{array}$ \\
\hline Brasil & 5570 & 142 & 155 & 100 & 117 & 74 & 75 & 46 & 118 \\
\hline Sul & 1191 & 42 & 45 & 32 & 30 & 17 & 16 & 8 & 32 \\
\hline $\begin{array}{l}\text { Paraná } \\
\text { Santa }\end{array}$ & 399 & 14 & 14 & 13 & 11 & 5 & 8 & 2 & 11 \\
\hline Catarina & 295 & 8 & 8 & 7 & 5 & 4 & 3 & 2 & 7 \\
\hline $\begin{array}{l}\text { Rio Grande } \\
\text { do Sul }\end{array}$ & 497 & 20 & 23 & 12 & 14 & 8 & 5 & 4 & 14 \\
\hline
\end{tabular}

Fonte: IBGE, Diretoria de Pesquisas, Coordenação de População e Indicadores Sociais, Pesquisa de Informações Básicas Municipais 2013 (compilado).

Conforme demonstrado, nem todos os estabelecimentos possuem o seu endereço mantido em sigilo - condição compreendida como necessária para a proteção da vítima.

Quanto ao atendimento psicológico individual (entendido como importante ferramenta para auxiliar no processo de superação da violência pela vítima) é disponibilizado em apenas $2 \%$ das Casas-abrigo em âmbito nacional e no estado do Paraná. Índice menor é encontrado quanto aos atendimentos psicológicos em grupo que ocorrem em apenas $1,5 \%$ das instituições.

$$
\text { Atividades culturais e }
$$
educativas são desenvolvidas nas CasasAbrigo em 1,3\% dos municípios do país, sendo $2 \%$ no estado Paraná. Somente $0,8 \%$ das cidades brasileiras contam com atividades profissionalizantes desenvolvidas em Casas-Abrigo, sendo que, no Paraná, o índice é de apenas $0,005 \%$. Quanto ao atendimento social acompanhado por assistente social que insira a mulher em programas sociais do 
governo, pouco mais de $2 \%$ das cidades no Brasil e no Paraná contam com tal iniciativa nas instituições de acolhimento de mulheres em situação de violência e risco.

Há que se ressaltar que a ausência da estrutura e atendimentos preconizados nas Casas-Abrigo afeta diretamente a vítima, interferindo negativamente e até mesmo impedindo no seu processo de resiliência e autonomia para a sua reinserção social e retorno ao lar.

\section{CONSIDERAÇÕES FINAIS}

O presente trabalho, através de levantamento teórico, possibilitou reconhecer a trajetória histórico-socialjurídica percorrida para o reconhecimento da problemática da violência contra a mulher e os esforços do Estado brasileiro para implementar uma Política Pública de proteção às mulheres.

Dentro desse cenário, a Política Nacional de Abrigamento direcionada a mulheres que se encontram em situação de violência com extremo risco e vulnerabilidade, se mostra como importante instrumento de operacionalização do seu atendimento, com ênfase na sua proteção.

Sua proposta abrange iniciativas de cunho multisdiciplinar e interinstitucional com o objetivo de acolher a vítima no momento de maior insegurança e trabalhar, em paralelo, com o desenvolvimento da sua autonomia e capacidade de resiliência visando o posterior retorno ao seu ambiente de origem.

Trata-se de uma proposta de atuação com grande potencialidade, mas que, contudo, também apresenta algumas limitações que precisam ser consideradas e aperfeiçoadas para que seja efetivo o trabalho com a mulher em situação de violência.

Dentre as limitações existentes, considera-se que há necessidade de proporcionar melhores estruturas nas Casas-Abrigo para que seja respeitada a condição essencial do sigilo. Este se apresenta como um pré-requisito para a implantação do serviço nos municípios, contudo, é apontado como de grande dificuldade por algumas administrações públicas municipais, uma vez que elas nem sempre têm a possibilidade da mudança constante do endereço das Casas-Abrigo (já que ex-acolhidas podem quebrar o sigilo do local, ou os 
autores de violência podem tomar ciência do endereço). Ademais, a própria característica desses municípios (especialmente de pequeno porte) pode dificultar a ocultação do endereço institucional.

Ponderando-se que as CasasAbrigo também devem ser criadas por lei, bem como estabelecer parcerias com outros serviços e Políticas Públicas por meio de instrumentos administrativos e legais, nem todos os municípios conseguem dispor da modalidade de atendimento institucional.

Por outro lado, quando instalado o serviço, de forma geral, ele costuma estar vinculado à Política de Assistência Social (já que o serviço foi incorporado na tipificação dos serviços socioassistenciais), o que, por sua vez, representa às Casas-Abrigo maior chances de manutenção do seu funcionamento.

Considerando que a situação do abrigamento pressupõe a existência de grave ameaça e risco à mulher, as Diretrizes Nacionais para o Abrigamento de Mulheres em Situação de Violência indicam a importância da articulação com a segurança pública também através de parcerias formais - condição essa que nem sempre se mostra possível em determinados municípios, especialmente nos de menor porte, uma vez que as estrtuturas não costumam ser ampliadas nesses locais.

De forma geral, nota-se que não existe um único fluxo de encaminhamento da mulher em situação de violência ao acolhimento institucional, tendo sido realizado de diferentnes formas em estados e municípios. Nesse contexto, pode haver encaminhamentos incorretos para o serviço que representam custos às CasasAbrigo e às próprias mulheres pelo encaminhamento menos efetivo às suas demandas e à realidade a qual pertencem.

Também se identifica que a minoria das Casas-Abrigo disponibiliza os atendimentos multidisciplinares indicados para a superação/minimização das sequelas biopsicossociais deixadas pela violência sofrida, bem como para a promoção da autonomia e contribuição para o processo de resiliência da mulher acolhida.

De modo semelhante, o acompanhamento pós abrigamento também se apresenta deficitário nessas instituições. Conforme as Diretrizes Nacionais, o processo de desabrigamento deve ser acompanhado 
pelo Centro de Referência Especializado de Assistência Social mais próximo da residência da vítima para que sejam articuladas estratégias que garantam o acesso da mulher ao mercado de trabalho, a programas sociais, de habitação e de geração de renda, conforme cada caso - o que nem sempre ocorre pela falta de disponibilização dos respectivos serviços ou ainda pela ausência de articulação entre os setores e Políticas Públicas.

Todavia, do mesmo modo que a atuação intersetorial conjunta pode se apresentar como limitação do trabalho, também pode ser compreendida como potencialidade do serviço de acolhimento institucional, uma vez que, com estratégias construídas e propostas de atuação alinhados, equipamentos da Rede de Proteção e Casas-Abrigo, juntos, tendem a contribuir de forma efetiva para a superação das situações de violência vivenciadas por mulheres. Por consequência, o empoderamento feminino também acaba sendo estimulado minimizando as chances da sua revitimização.

\section{REFERÊNCIAS}

66

BRASIL. Casa da Mulher Brasileira.

Secretaria de Políticas para as Mulheres.

Disponível

em: $<$ http://www.spm.gov.br/assuntos/viole ncia/cmb>. Acesso em: 25 abr. 2016.

BRASIL. Diretrizes Nacionais para o Abrigamento de Mulheres em situação de risco e violência. Secretaria Nacional de Políticas para as Mulheres/Secretaria Nacional de Enfrentamento à Violência contra as Mulheres. Brasília: 2011.

BRASIL. Lei $n^{0}$ 9.807/99. Estabelece normas para a organização e a manutenção de programas especiais de proteção a vítimas e a testemunhas ameaçadas, institui o Programa Federal de Assistência a Vítimas e a Testemunhas Ameaçadas e dispõe sobre a proteção de acusados ou condenados que tenham voluntariamente prestado efetiva colaboração à investigação policial e ao processo criminal. Promulgada em: 13 de julho de 1999.

BRASIL. Lei $\mathbf{n}^{0}$ 11.340/2006. (Lei Maria da Penha). Cria mecanismos para coibir a violência doméstica e familiar contra a mulher e dá outras providências. Promulgada em 07 de agosto de 2006. 
BRASIL. O Poder Judiciário na Aplicação da Lei Maria da Penha. Conselho Nacional de Justiça, 2013. Disponível em: http://www.cnj.jus.br/images/Maria\%20 da\%20Penha_vis2.pdf. Acesso em: 20 ago. 2016.

BRASIL. Pacto Nacional pelo Enfrentamento à Violência contra a Mulher. Presidência da República/Secretaria Especial de Políticas para as Mulheres. Brasília: 2007(a).

BRASIL. Plano Nacional de Políticas para as Mulheres. Presidência da República/Secretaria Especial de Políticas para as Mulheres. Brasília: 2005.

BRASIL. Portaria MS/GM 936, de 18 de maio de 2004: rede nacional de prevenção da violência e promoção da saúde e a implantação dos núcleos de prevenção da violência em estados e municípios. Diário Oficial da União, Brasília, DF, nº 96, 20 mai. 2004. Seção 1e.
BRASIL. Recomendação nº 09/2007.

Conselho Nacional da Justiça.

Publicado em 08 de março de 2007(b).

BRASIL. Resolução $\mathbf{n}^{\mathbf{0}} \quad$ 109/2009. Aprova a Tipificação Nacional de Serviços Socioassistenciais. Ministério do Desenvolvimento Social e Combate à Fome/Conselho Nacional de Assistência Social. Publicado em 11 de novembro de 2009.

BRASIL. Resolução $\mathbf{n}^{\mathbf{0}} \mathbf{1 2 8 / 2 0 1 1 .}$ Determina aos Tribunais de Justiça do país a criação de Coordenadorias Estaduais da Mulher em Situação de Violência. Conselho Nacional de Justiça. Publicado em 17 de março de 2011.

BRASIL. Termo de Referência para a Implementação de Casas-Abrigo. Secretaria Nacional de Políticas para as Mulheres. Brasília: 2008.

BRASIL. Tipificação Nacional de Serviços Socioassistenciais. Ministério do Desenvolvimento Social e Combate à Fome/Conselho Nacional de Assistência Social. Brasília: 2013.

DIAS, Sandra Pereira Aparecida. Um breve histórico da violência contra a 
mulher. 2010. Disponível em: ov.br /materias/anteriores/edicao21/ http://araretamaumamulher.blogs.sapo.p materia03/. Acesso em: 04 set. 2015.

t/16871.html. Acesso em: 04 set. 2015.

IBGE. Perfil dos Municípios

Brasileiros 2013. Disponível em: http://www.ibge.gov.br/home/estatistica /economia/perfilmunic/2013/defaulttabz ip_ods.shtm. Acesso em: 05 jun 2016.

IPEA. Violência contra a mulher: feminicídios no Brasil. Instituto de Pesquisa Econômica Aplicada, 2013. Disponível em: $<$ http://www.ipea.gov.br/portal/index.ph p? option=com_content\&id=19873>. Acesso em: 26 jun. 2015.

PEREIRA, Malila Natasha da Costa; PEREIRA, Maria Zuleide da Costa. A violência doméstica contra a mulher. In: Revista Espaço do Currículo, v. 4, ${ }^{\circ}$ 01: João Pessoa, 2011.

PINAFI, Tânia. Violência contra a Mulher: Políticas Públicas e medidas protetivas na contemporaneidade. In: Revista Histórica. Edição $\mathrm{n}^{\circ}$ 21. São Paulo: Arquivo do Estado, 2007. Disponível em: http://www.historica.arquivoestado.sp.g
RIBEIRO, Marcelle. IBGE: 97,5\% das cidades não têm casas-abrigo para mulheres. Disponível em: http://noticias.terra.com.br/brasil/cidade s/ibge-975-das-cidades-nao-tem-casasabrigo-paramulheres,51927ea7920b5410VgnVCM 4000009bcceb0aRCR D.html. Acesso em: 05 jun. 2016.

\section{SÃO PAUlO. Portaria NUDEM $\mathbf{n}^{\circ}$} 37/2009. Núcleo Especializado de Proteção e Defesa dos Direitos da Mulher / Defensoria Pública do Estado de São Paulo. Referente aos reflexos do projeto de Lei do Senado n ${ }^{\circ}$ 156/09 que trata da reforma do Código de Processo Penal, na Lei Maria da Penha. Disponível em: Portaria/0http://www.defensoria.sp.gov. br/dpesp/repositorio/PP\%20e\%20Lei\%2 0Maria\%20d\%2037\%2009\%20Reforma \%20do\%20C.a\%20Penha\%20final.doc. Acesso em: 07 ago. 2016. 